\title{
GENDER POSITIONS AND HIGH SCHOOL STUDENTS' ATTAINMENT IN LOCAL GEOMETRY
}

\author{
Received: 4 January 2013; Accepted: 19 March 2014
}

\begin{abstract}
Several studies that suggest for the inclusion of students' cultural background into the mathematics curriculum fail to address gender roles within cultures and the impact it will have on the understanding of academic mathematics. This paper reports a study of high school students' involvement in everyday material production and its connection to geometric performance, on 20 students from a rural setting secondary school, in Tigray, Ethiopia. An interview involving six questions each followed by a mathematical question was administered to the group of participating students. The analyses of the interview and the mathematical questions have come up with the following findings: (1) some everyday materials are identified as male-orientated and hence, the male students show better fluency in basic geometry for practical utility which have connections with their domain; (2) some other activities and the production of everyday materials are found as female-orientated and therefore, the female students demonstrated better performance in using basic procedures of geometry for practical utility; (3) both males and females demonstrated an enhanced transformation of the local mathematics into a corresponding global in relation to their domain-orientated activities; and (4) some other activities are found to be well (or equally)-orientated.
\end{abstract}

KEY WORDS: culture, ethnomathematics, female-orientated activities, gender, global mathematics, male-orientated activities, multicultural mathematics, well-orientated activities

\section{INTRODUCTION}

Existing mathematics curricula have come under increasing inspection for their consideration of culture all over the globe. Suggestions for comprehensive reforms originate in part from research-based knowledge of how students construct their own knowledge based on their cultural background and how the contents of mathematics can be organized for effectual teaching and meaningful student learning. Conversely, the argument also covers discussions of what mathematics is worth knowing and doing in our swiftly changing society. Several reports recommend a new vision and possibilities for the mathematics curriculum with regard to multicultural mathematics (Bishop, 1993; D’Ambrosio, 1990; de Abreu \& Gorgorio, 2007; Alro, Skovsmose \& Valero, 2007). The empirical support for this area is vast, but partial because most of the research 
reports emphasized merely on the inclusion of multicultural mathematics in the curriculum than identifying the role of social groups related to practical activities that have mathematical significance within a culture. Thus, except few that provides some directions (e.g. Nichol \& Robinson, 2000; Zaslavsky, 1994), research studies that report on the role of social groups (age group, gender, competent adults, etc.), particularly, genderrelated activities in a given culture are rare.

If cultural background of students is considered as something that matters on students' understanding of mathematics, there is a need to assess these everyday materials and activities that are gender-orientated, gender free, and their significance to mathematics education. Matang (2002) argues that much linkage is evident between everyday cultural practices of geometric significance and the abstract concepts found in school mathematics. Taking this in to account, this paper attempts to provide answers for the following two research questions related to everyday materials of geometric significance.

1. What is the degree to which high-achieving male and female students are engaged equally well in everyday activities having geometric significance in their community?

2. What is the effect of the domains-based everyday activities on highachieving students' geometric performance and in interpreting these everyday materials of geometric significance into their corresponding global geometric concepts?

\section{Conceptual Framework}

\section{Perspectives on Gender Positions in Mathematics Learning}

For the purpose of this paper, Gender difference in mathematics, which is liable to change, refers to a non-biological trait of people, attributed to psychological features and social categories in the learning of mathematics. Scholars have attempted to explain attributes that contribute for gender difference in mathematics learning and achievement. Two views prevail with regard to gender difference in mathematics learning: (a) one that reflects genetically rooted sex difference in math ability (Benbow \& Stanley, 1983) and (b) the other that reveals the difference as gender-role socialization and/ or stereotype threat (Eccles, 1987; Fennema \& Sherman, 1987; Levine \& Orbsteub, 1983; Deaux \& Major, 1987; Spencer, Steele \& Quinn, 1999). Studies have challenged the first view that gender difference in mathematics 
is, due to the genetically rooted sex difference in math ability. Leder (1992) as well as Spencer et al. (1999) believes that the difference is due to genderrole socialization and gender stereotype threat respectively. It is generally understood that the range of factors attributing for gender difference in mathematics learning is enormous since such a list would include: educational opportunity, teaching styles, societal values and influences, ways females and males are socialized, the social environment, students' reaction to the cultural and more immediate contexts in which learning takes place, the cultural and personal values placed on the learning and the inclusion of learner-related affective and cognitive variables. Apparently, these variables will have potential dark sides on female students' future achievement and performance in mathematics. Nieminen, Savinainen \& Viiri (2013) conducted a compelling case study that supports this position. In their finding, it was reported that gender difference in mathematics and physics is much related to students' prior knowledge, attitudes, and beliefs.

The study of factors attributing for gender difference in mathematics gained momentum in the last two-three decades. Some studies found that males did not outperform females in those that involve knowledge of procedures and algorithms, but did outperform them in course work that entail advanced problem solving beginning from the high school (Hyde, Fennema \& Lamon, 1990; Armstrong, 1981; Ethington \& Wolfe, 1984). Specifically, in their review of gender-related geometry differences, Clements \& Battista (1992) found that males significantly outperformed females for all cognitive levels (knowledge, skill, understanding, application) and all ages. These differences might reflect the influence of differential socialization and/or stereotype threats which are most evident on difficult and advanced materials. It is believed that these factors result in trepidation that may disrupt females' math performance.

Recent research reports on gender difference in mathematics offer some hope for changing the negative stereotype threat that females have weaker math ability. In particular, Leder (2008) reported that females outperformed their male classmates in open-ended and context-rich problems in a number of nations: Iceland, Iran, and Australia. Indeed, in history, females are the first people who have engaged in the struggle to observe and understand nature since the ancient societies; thereby contributed to the development of mathematics (Izmirli, 2011).

\section{Interplay Between Culture and Mathematics}

Addressing distinctions and commonalities among the concepts culture, local culture, globalization, and global culture will worth understanding 
many things when comes to specific subjects, such as mathematics. Culture, according to Pollard (2002) is the knowledge, stances, and routine activities shared and conveyed by the members of a society. Culture includes several things that have unswerving implication for teaching and learning: ethnic group's cultural values, traditions, communications, learning styles, contributions and relational patterns. Specifically, the educational stakeholders should know the implications of gender-role socialization in different ethnic groups for implementing equity initiatives in classroom instruction (Gay, 2002).

Local culture, on the other hand, is the experiences, customs, and traits exercised by a group of people in a particular place who see themselves as a collective or a community and who work to maintain those traits and customs in order to claim uniqueness and to distinguish themselves from others (Moreira, 2007). Globalization is then a process by which people in a local place mediate and alters national, regional, and global processes and thus global culture is the global interconnectedness, which posits the world consisted of an interrelated series of interaction that expand across space. All people, where no exception is made between males and females, are cultural artistes, and thus, mathematics, a human creation, is at the heart of culture. Thus, most cultures, as human products, including mathematics, have both theoretical and philosophical foundations that they have to be working in. Bishop (1988) as well as Zaslavsky (1993) maintained that, mathematical discoveries and objects as cultural products arose out of the real needs and interests of people regard less of their: ethnicity, location, and time of experience.

Understanding the cultural nature of mathematics is well embedded on the understanding of the philosophy as well as the theoretical views of mathematics (Bush, 2005; Izmirli, 2011). However, the view of mathematicians on the nature of mathematics is divided, while some promote the view that mathematics as internal to the learner, others advocate the view that mathematics is external to the learner (Gold, 2011; Dossey, 1992). For example, from the theoretical perspective, the social constructivists view mathematical objects as culturally produced and thus internal to the learner, whereas from the philosophical viewpoint, Platonists view mathematical objects as real and external to the learner that she/he has to explore as scientists discover a new planet in the universe.

Bishop (1988) and Zaslavsky (1994), who are amongst the leading scholars on culture and mathematics, offer their support to the former-that mathematics is a cultural product that has developed because of multifaceted activities within a culture. They argue that all 
people mathematise, with corresponding language to communicate their mathematical rigor to others. In particular, the cultural product that Bishop (1988) investigated to be common to all cultures include the following: counting, locating, measuring, designing, playing, and explaining.

It is generally agreed that the study of ethnomathematics as a program helps to realize mathematics as a cultural product and thus looks into the dissemination of knowledge with emphasis on the socio-cultural environment. In a broader context, ethnomathematicians such as D'Ambrosio (1985), Gerdes (1985), Joseph (2000), and Powell \& Frankenstein (1997), who established the theoretical, epistemological, and philosophical foundations of ethnomathematics, believed that mathematics is a cultural product and that every culture has developed its own forms of mathematics. Based on D'Ambrosio's (1985) definition of ethnomathematics, who is a pioneered author in this subject, Vithal \& Skovsmose (1997, p.133), offered an all-encompassing and comprehensive definition that cluster the varied dimensions of ethnomathematics: "Ethnomathematics refers to a cluster of ideas concerning the history of mathematics, the cultural roots of mathematics, the implicit mathematics in everyday settings, and mathematics education." Thus, ethnomathematics is the way different cultural groups mathematise (e.g. count, measure, relate, sort, compare, infer, hypothesize, problem pose, generalize, communicate, data gather and process, predict, analyze, record, evaluate, verify, and construct).

It seems reasonable to say that, Ethnomathematics aims not only to highlight the role of all cultures inputs to mathematics equitably but also to entertain methods and strategies of doing mathematics in varied cultures. Further, it establishes linkage between local mathematics and global mathematics for the lucid and intelligible interpretations of exchanges that exist between the local and global dimensions of the society. Local mathematics according to Moreira (2007), is the mathematics implicitly embedded within the cultural activity of a particular community and the way people in that community mathematise; whereas global mathematics is a translation of the mathematics embedded in the local cultural activity into a formal academic and that can be readily interpreted by participants of mathematical activity in other cultures. For Moreira (2007), while the global aspect helps students be aware of the mathematics related to economic development, technology, and democratic competence, the local aspect helps students develop their own methods and strategies to cultural or everyday practices of mathematics of their particular culture and to assure its continuity. 
The key to the teaching and learning of mathematics, the theoretical foundations, where the philosophies and principle of mathematics instruction is supposed to underlie related to any cultural context, will be discussed at some length in the section that follows.

\section{Theoretical Views on the Nature, Learning, and Teaching of Mathematics}

A range of theoretical views including constructivist, social constructivist, and socio-cultural views of learning, all place emphasis on the role of students' cultural background in mathematics learning. These theories constitute the most public theories of education, including those apt for mathematics education, appeared recently (Rogoff, 1999; Cobb, 1999). In contrast to "mathematics as something you are taught first and apply second", these theories promote a more learner-oriented approach to learning. These theories support the position that culture and the social context of the student influence his/her understanding of mathematics (Vygotsky, 1978; Boaler, 1993; Ernest, 1996; Von Glasersfeld, 1996; Piaget, 1980). Thus, when students experience this culture and context, they assimilate particular cognitive skills, strategies, knowledge and understanding (Dunn, 1988). These theoretical views appreciate the issues related to culture and enthusiastically advocate a model of learning and view of knowledge authentically sensitive to both culture and mathematics.

Some studies (e.g. Bishop, 1991; Pinxten, 1994) have shown significant mismatch between students' cultural background and the mathematics taught in schools. To address this issue, many scholars have suggested on teaching and learning of mathematics in culturally specific contexts. With regard to this view, two themes prevail: (a) using relevant cultural examples from students' lives (e.g. Moses \& Cobb, 2001; Gerdes, 2001; Mallory, 1997) and (b) exposing students to a variety of cultural contexts - a multiculturalism approach (e.g. Zaslavsky, 1998; Dolinko, 1997; Presmeg, 1998), which can be defined as exposing students to the mathematics of different cultures so as to increase their social awareness, to reinforce cultural self-respect, and to offer a cohesive view of cultures (Bush, 2005; Rosa \& Orey, 2010). Multicultural approach must assure cultural bridging in a way that breaks down personal and cultural barriers, and create an environment in which all students can develop confidence and pride about their culture. For Stredder (1999), there are three ways of attaining cultural bridging in a culturally diverse classroom. The first of these is the teachers' choice and use of knowledge about minority cultures in a way that facilitates learning by creating opportunities for participation, 
interaction and cognitive challenge. This has a lot in common with Gay's (2002) suggestion of culturally responsive teaching which focuses on the cultural roots of the diverse learners that increases gender relations/ interactions. The second is introducing through task-setting which allows students to draw on their cultural experiences which might take the form of working collaboratively with other children on activities drawing from their own personal experiences. A third kind of cultural bridging encourages children to acknowledge different languages, religious practices, and cultural traditions in their social interactions and activities in the classroom. These perspectives reject the prevailing methods of teaching which treat mathematics as a deductively discovered, pre-existing body of knowledge.

\section{Design Of The Study}

This section will report on the way data were gathered and processed, the research design and the procedures followed in order to reach valid conclusions.

\section{Procedures}

As a first step in this research, a preliminary interview was conducted over half of the participants. From this participants' response, some patterns were discovered-the classification of some activities and everyday materials of geometric significance as: domain-orientated or domain-free. The second step was to get an approval from competent adults if these classifications really hold. Ten competent adults (five females and five males) were selected to have strong cultural background: knowledgeable, well-skilled, and experienced in the production and development of these daily materials, and well involved in cultural activities. Thus, the daily activities and material production that are acknowledged as male-domain are termed by the researcher as male-orientated (MO). A rough criterion that distinguishes the male-orientated activities include: require more muscle work, energy, and exposed to high risks. (2) Some other activities and everyday materials were classified as female-domain. The researcher would like to call them as female-orientated (FO). Most of these activities and productions: require considerable time, call for systematic/careful planning and much abstraction, involve high concentration and attentiveness of patterns, and that can run with minimum muscle work and energy. (3) Whether the materials are male produced, female produced (finished product) or appear naturally, there are 
activities that offer equal opportunity for both males and females to involve in. The researcher recognized these as well/equally orientated (WO). These activities are equally accessible for both genders. Although there are many everyday activities that resemble for the domain-based or domain-free activities, only six of these were selected as representatives (see Table 1).

There are reasons why everyday materials or activities of geometric significance were the focus of this study. For one thing, Matang (2002) argues that it is not the finished product of geometric significance that it

\begin{tabular}{|l|l|l|}
\hline Local Material (Picture) & Corresponding Global Picture & Measurements \\
\hline & & \\
\hline & & \\
\hline
\end{tabular}

TABLE 1

Local materials, global pictures, and measurements 
matter, it is the mathematical idea embedded within that activity (the planning, the structure, the imagined shape, the perceived spatial relationship between object and purpose, the abstracted form and the abstracting process) that it matters to mathematics education. And for the other thing, Goldberg, Cuoco \& Mark (1997) outline two broad claims that support Matang's position: geometry can help students connect with mathematics and geometry can be an ideal vehicle for building the habits of mind perspective.

\section{Participants}

The subjects of this study included 20 grade 11 students from rural setting secondary school in Tigray, Ethiopia. All of the participants received prior instruction on the basics of geometry (both 2-D and 3-D) in their formal mathematics classes in the elementary through the secondary schools. Moreover, these students are in the category group of "highachieving" students in mathematics as they scored A or B in mathematics in particular and distinction or above $(\geq 3.25$ out of 4.00$)$ in the tenth grade leaving certificate national examination in general. The researcher decided to include these groups of students because they could precisely inform about the level to which everyday materials of cultural significance are considered in the curriculum and their particular roles and practices in the community in gender-related activities that have relevance to geometry.

\section{Instruments of Data Collection}

The Interview-Mathematical Question Tool. This instrument had two parts: the interview section and a mathematical question following each interview question. The interview questions were developed to assess students' degree of involvement in the production of cultural materials that have mathematical significance and thereby identify participants' use of strategies and reasoning, probe the depth of understanding of procedures and observe participants' use of representations or materials. The interview is a semi-structured one involving oral explanations for transcription and a task-sheet that helps respondents to write their views on a space provided for writing responses when found necessary.

On the other hand, the mathematical test aims to measure participants' ability in transforming a local mathematical knowledge into its corresponding/equivalent global. For example, a typical interview item and a corresponding mathematical question are given below: 
Interview Item: a) What is this shape? b) Describe a complete procedure in building/constructing this shape; c) Determine the aspects that will affect the quality of this material; d) what mathematical concept is embedded in it? e) How frequent are you engaged in the production of everyday materials of such a type? f) Are such types of activities included in your textbooks? Explain it and give your recommendations!

Mathematical Question: Set a global picture corresponding to this image of a local material. Label it and find every measurement related to the global picture you have drawn. You are also required to establish important relationships among the labels.

Table 1 displays the local materials cited in the first column and its expected corresponding global pictures and measurements to be completed in columns two and three, respectively where justification is required for established relationships among labeled quantities by participants. The interview and mathematical questions related to local materials for interpretations were accompanied with images taken using a digital camera by a professional photographer.

The researcher made a thorough look on the images taken by the professional if these images meet basic principles and assumptions, representativeness, as well as distinctiveness that have acceptance by the community. It was believed that the inclusion of these images in the tasksheet adds clarity for the population of participants.

The Scoring Guide/Rubric. A five-level scoring guide/rubric ranged from level 0 to 4 (Table 2) was used to determine the average score of every participant on the mathematical questions. This was so because the researcher believes the problems are open-ended and context rich. That means the participants solutions to the problems will be managed more meaningfully if such an instrument is used cautiously. The instrument was adapted from Kuhs (1994) with certain modification to fit the research goal. Each participant was encouraged to submit a complete solution of each problem $2 \mathrm{~h}$ after the interview.

\section{Data Analysis}

Interviews as immediately followed by the mathematical questions were conducted on six separate days with the two cohorts for it take considerable time with an individual interviewee and in writing answers/solutions to the mathematical questions. Notes were taken during interviews, and each interview was audio taped and transcribed for 
TABLE 2

General scoring rubric

Level 4: The participant

- Provides accurate and complete information of the problem situation.

- Demonstrates appropriate use of given information to back conclusions with data and warrants.

- Uses appropriate strategies or approaches that logically related to the problem.

- Commits no errors in mathematical procedures.

- Evidences creative or insightful approach to the problem situation.

Level 3: The participant

- Gives accurate but only adequate information of problem situation.

- Evidences appropriate use of given information but fails to back conclusions with data and warrants.

- Uses strategies or approaches that logically relate to the problem often.

- Commits few mathematical or procedural errors.

- Evidence that answers were usually evaluated in the context of the given problem frequently.

Level 2: The participant

- Demonstrates accurate interpretation of problem situation or statements occasionally.

- Evidences occasional incorrect use of the given information.

- Shows inconsistent use of strategies or approaches that logically related to the problem.

- Commits errors in basic procedures commonly.

- Produces answers not have been related to the given problem situations.

Level 1: The participant

- Makes an inaccurate interpretation of the problem or incorrect use of given information.

- Rarely uses strategies or approaches that logically relate to the problem.

- Commits errors in basic procedures frequently.

- Produces answers that have not been evaluated in the context of the given situation.

Level 0: The participant provides incomplete answer or the answer does not meet any of the mentioned criteria.

analysis. The instrument was administered during summer breaks where participants had no chance for communication.

Coding was based on interview transcripts. To assess coder reliability, two coders were trained and given interview transcripts for three individuals from each cohort, totaling 6. In this regard, inter-rater agreement on coding was 113 agreements out of 120 decisions, or $94 \%$ agreement. This is realized as a high inter-rater agreement.

Also, the participants' solution to the mathematical questions following each interview question and an interpretation of the local to a corresponding global were rated using a five-level scoring guide/rubric (Table 2). Then $t$ test 
was run to assess the level of significance between the mean differences of the two groups using the statistical package called SPSS. To assure reliably of the mathematical test, Spearman-Brown Prophecy formula, that is, the half-split or odd-even reliability procedure was used to get the correlation of 0.82 and hence, the reliability of the whole test was calculated as $\frac{2 \text { (reliability of } 1 / 2 \text { test })}{1+(\text { reliability of } 1 / 2 \text { test })}=\frac{2(0.82)}{1.8}=\frac{1.64}{1.82} \approx 0.90$. As illustrated, the reliability of the whole test is estimated to be higher $(0.90)$ than the correlation between the odd and the even scores (0.82). With the assumption that the two halves are parallel and the test is relatively long, the half-split reliability test implies that the level of internal consistency of the test.

\section{Results And Discussion}

In this section, participants' responses to the interview and mathematical questions following each interview question are interpreted in relation to the two research questions raised in the "Introduction" section.

Question 1. What is the degree to which high-achieving male and female students are engaged equally well in everyday activities having geometric significance in their community?

This question could be answered when viewed with regard to everyday materials and activities that are gender-orientated and gender free as portrayed below.

\section{Male-Orientated Everyday Situations and Activities (Pictures 1 and 2 in} Table 1)

Because the society places the students in a position of gender-focused or gender-orientated activities at large, the aim was to investigate the impact this would have on students of a gender in demonstrating reasonable mathematical interpretation and performance. In this regard, all of the male students affirmed that they could state the complete procedures in constructing the local house and the local storage (first two pictures in Table 1) as well as ready to list down the mathematical concepts embedded in producing the material as they are trained by competent males. For example, Hafte, who is one of the male students, described the complete procedure in constructing the daily material (the local house) and the mathematical concepts embedded in it. He stated:

First you need to determine the size of the house based on a radius which determines the area of the floor. You need to fix the anchor to determine the center which is the place for 
the axis. Then, the circle is determined around which the cylindrical shape is built. In doing this, ... the concept of a circle, the concept of a cone, and the concept of an axis which connects the vertex of the cone with the center of the circle as a base of the cylinder are used.

Tukab, a male student evidenced similar sentiments to Hafte's ideas. He modeled the situation as indicated in Figs. 1 and 2 below. He also explained the factors or attributes that will affect the quality of the house. He explained:

The axis is important in keeping the balance of the house. It fixes its position quite erect. It [the house] also depends on the quality of the roofing. A highly erect roof is as bad as a flattened roof . . . . A good house is the one whose distance from the upper circle to the axis is equal to the distance from the same point on the axis to the disk- "walta".

However, the measurement of the house was entirely local. They measure in arms called "Emets" and walks called "sidaros." Hilufen, another male student explained how the sizes of houses are determined and the name offered for them. He elucidated:

We measure the size of the rope as measured in number of 'Emets' - arms. A three-arm rope measures 'Bet six'-measured in relation to the length of the diameter. 'Bet-six' is a 'round mud-and-wattle' house whose diameter of the floor is six 'Emets'. The biggest house is usually 'Bet 12 ' - a house of diameter 12-'Emets'. Today we also use meters in place of arms or 'Emets'.

Here, it shows a good exchange between local and global knowledge demonstrated by this student.

The female students, on the contrary, demonstrated weaker explanations and descriptions of the procedures in building the houses of the type

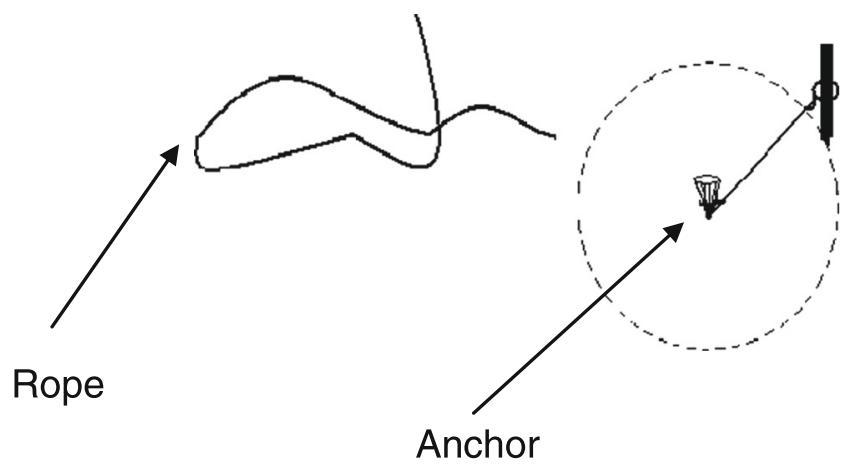

Fig. 1. The mathematical process of building a local house (rope and anchor) 


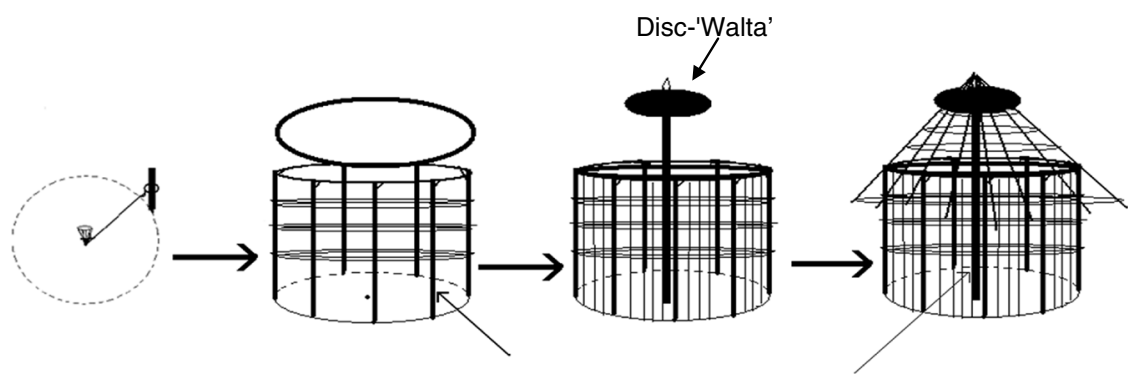

Fig. 2. The mathematical process of building a local house

and the aspects that affect its quality. Birhane, one of the outstanding female students is a case that illustrated the situation. When asked to state the procedures of constructing these everyday materials and list the factors that affect its quality, she stated,

"I did not have the idea ... it is mostly a male activity. We are not allowed to engage in such male focused activities. . . .I think it is made of something [some material] I know but I did not knowhow it [the house] is made."

When required to describe the daily material and how it is made procedurally, as well as why it was given that shape as a storage, the male students demonstrated success in coming with reliable responses. Hagusa who is a preparatory student and his friend Mehretu provided similar sentiments to the questions in problem 2. Hagusa clarifies the procedures of construction with a rough sketch depicted in Fig. 3, why the everyday material took that shape, and quality management. He stated his idea which actually illustrates ability in interpreting a local mathematical knowledge to its equivalent global mathematics as follows:

This is called Solo-locally "Gotera". This is where we store our crops. Its construction is very similar with the procedure for building the house except possibly the inverted lower cone. It will help prevent damage as a result of decay. You can easy mange the actions and damages that can happen by termites, ants, and decay because of bacteria. It doesn't have direct contact with the earth/ground and it is well-aerated.

Male students found it motivating in providing a corresponding global picture and finding the measurements of the solid of such a type-its volume, surface area, and the length of the axis connecting the two vertices. Figure 3 and the second diagram in column one of Table 1 displays the situation.

On the contrary, the responses obtained from all female students were worrisome. They indicated little idea with regard to the construction of 
Fig. 3. Gottera

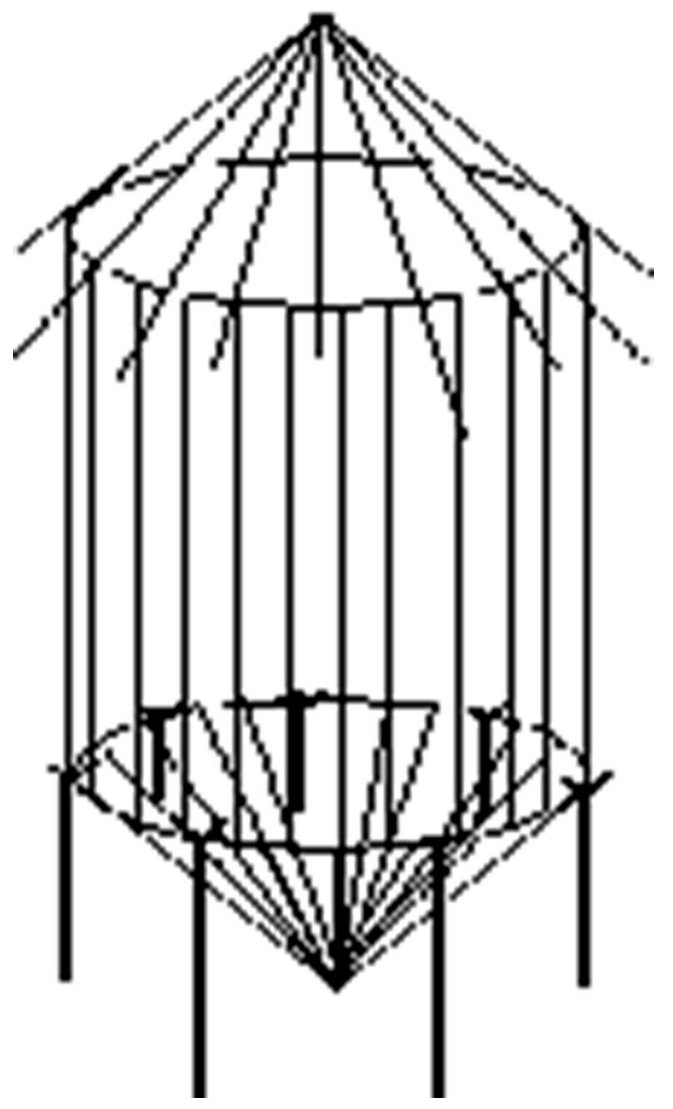

the material, the mathematics embedded in it, why the material take that shape, and the aspects that will affect its quality except possibly witnessed it is used for storage. They did not tell how these circles, cones, and cylinders are made as well as the mathematics embedded in them.

The reasons for these were apparent. While the females were denied access to learn these activities of mathematical significance, the male students were encouraged because these were identified as male-domain in the community they are engaged in. To that end, one of the female students stated "I had not had any involvement because competent adults (males and/or females) did not allow us to engage in such male-domain activities. But I think we can do it by simply digging circles . . . Is that not? . . otherwise I do not have any idea." This lacks an appropriate integration of the global and local mathematics as complementary aspects 
of multicultural mathematics so that learning makes sense on the side of students.

\section{Female-Orientated Everyday Materials and Activities (Pictures 3 and 4 in Table 1)}

Because these activities are entirely accomplished by females, though commonly used by everyone in the society as a finished product, the female students perform well in demonstrating the complete procedures in making these daily materials (see the third and fourth diagrams in Table 1). It must be noted that all the participants had no problem in providing appropriate terminology/naming for the daily materials of mathematical significance. The interviews revealed that the female students, far better than the males, described the procedures of constructing the daily materials, their applications, and the mathematics embedded in it. Breheta, one of the female participants explained how each of the indigenous technologies is build. She went explaining:

First you need to have the locally available row materials relevant to build it. It involves some special grasses, such as "sendedo". . . there are special patterns in building the seat for coffee pot which is a combination of two frustums of circular cones and serving dish/ tray which is a combination of a right circular cone and a portion of a sphere. Then you went on sewing increasing the diameter of each circular portion to enlarge the size of the daily material which will result in the desired shape...

However, all males provided answers that have little connection to the construction process. When asked on the procedures that one has to follow and the mathematics embedded in these everyday materials, their responses were just below expected. Most said, "I think it is made of spirals ... females made it as they are female focused and acknowledged." Although many educators (e.g. Bishop, 1992) argue that the cultural perspective endorses the centrality of people in education and helps to demonstrate that mathematical knowledge is constructed, interpreted and shaped by people as owners of that culture, this current study evidences the disparity of people within a culture with regard to the knowledge they have to own as a member of a particular community.

\section{Well/Equally Orientated Everyday Situations and Activities (Pictures 5 and 6 in Table 1)}

As mentioned earlier, some activities that members of the society engaged in are found to be domain-free. They are named so because the degree of engagement of both genders, and the knowledge and understanding of 
mathematical content embedded in these activities between these two cohorts are found to be comparable. Both males and females showed nearly equally likely ability in translating and interpreting local mathematics into its formal school mathematics. Silas, who is a female student, explained her idea as follows:

When we walk from place to place, we are very selective (see diagram 5 in Table 1). We never walk as we like. If the path from $\mathrm{B}$ to $\mathrm{C}$ is equally safe as going through $\mathrm{A}$ to $\mathrm{C}$ beginning at B, why do I go this long way and kill my time? Suppose the distance between any two destinations be equal. If one chooses walking straight from $\mathrm{B}$ to $\mathrm{C}$ it requires half the time walking along $\mathrm{A}$ then to $\mathrm{C}$ beginning at $\mathrm{B}$. We call this the shortest way connecting two destinations-in local terms 'Aquarach'.

Emanuel, a male student even went further and explained in relation to the formal school mathematics. He maintained that:

When I was in the village, I learned from parents, friends, and relatives that the shortest path is economical in terms of time and energy. In the school mathematics we learned it as the shortest path postulate. But this was more explicit when the topic triangular inequality was under consideration: 'the sum of any two sides of a triangle is greater than the third side.' Thus, the sum of the segments $\mathrm{AB}$ and $\mathrm{AC}$ is greater than the segment $\mathrm{BC}$. That means, the distance between $\mathrm{B}$ and $\mathrm{C}$ is shorter than the sum of the distances represented by $\mathrm{AB}$ and $\mathrm{AC}$.

Enshu, who is a female student, also demonstrated her understanding of division of a whole among a given number of individuals (in this case among eight friends). Her procedure of dividing the local circular bread (see diagram 6 in Table 1), typical to the Tigrean people in Ethiopia, involves the concept of symmetry. Enshu elaborated this local knowledge of mathematical significance into its equivalent global mathematical idea using division of the circular bread as fair share performed among eight friends. She commented that:

We frequently practice this division among family members, friends and others. For example, I can do this very easy. First I fold the circular bread once to get the halves. That means I will cut it along the diameter. Then, I will fold the half circulars to get the quarters. That means, the half of a half is a quarter. In the end, I will fold the quarter pieces into halves. That means the half of a quarter is an eighth. At this time every one of the friends received approximately an eighth of the circular bread.

In terms of school mathematics, this is the application of symmetry. This indicates that global process are re-interpreted and re-appreciated in relation to the local culture. According to Moreira (2007), this involvement helps in constructing linkages between ways of thinking and acting locally and ways of thinking and acting in other ways of society. 
Question 2. What is the effect of the domains-based everyday activities on high-achieving students' geometric performance and in interpreting these everyday materials of geometric significance into their corresponding global geometric concepts?

This research question is answered more based on the analysis of participants' written responses to the mathematical questions and to some extent from the analysis of the interview questions. The mean scores which males and females obtained on the mathematical questions were compared by running $t$ test with regard to the three domains of activities: Male-Orientated (MO), Female-Orientated (FO), and Well/Equally Orientated (WO).

As the means in Table 3 show, some patterns did emerge. $F(1,20)=$ $3.15, p<0.01$ for MO indicating significant difference in performance scores between the male and female students in interpreting the local materials of mathematical significance into its equivalent global, with the male students outperforming the female students. The result of the analysis indicated females underperform in translating the local materials of mathematical significance in the male-orientated activities into their equivalent global mathematics.

On the other hand, $F(1,20)=2.35, p<0.05$ for $\mathrm{FO}$ in Table 3 indicating significant difference between the mean scores of the male and female students with females performing better than males in the femaleorientated activities. This result shows that males underperform as compared with females in the female-orientated (FO), because females far more than males were encouraged to be involved in these activities. This view lends support from Leder (1992) who argued gender-role socialization including: societal values and influences, the ways females and males are socialized, students' reaction to the cultural and more immediate contexts in which learning takes place are a contributing

TABLE 3

Cohorts' means (standard deviations) and level of significance in mathematical questions

Orientation category

\begin{tabular}{llll}
\cline { 2 - 4 } Cohort & MO & WO & FO \\
\hline Male & $7.2(0.98)$ & $6.2(1.26)$ & $4.2(1.67)$ \\
Female & $4.4(1.02)$ & $6.00(1.18)$ & $6.40(1.25)$ \\
$\begin{array}{l}\text { Significance between } \\
\quad \text { groups }\end{array}$ & $t=3.15, p<0.01$ & $t=0.24, p$-insignificant & $t=2.35, p<0.05$ \\
\hline
\end{tabular}


factors attributing for gender difference in mathematics learning. More specifically, the result of the case study on the 131 Finish students by Nieminen et al. (2013) has much in common with this research. They argue that prior knowledge together with attitudes and beliefs that secondary students owe towards mathematics and physics are major contributing factors in gender difference in these subjects. What is true to this study is also that when students are engaged in domain-based activities that have mathematical significance, they outperform the other in relation to the domain. Thus, the prior experiences in the community had an impact in their performance in the academic mathematics. Moreover, the taboo that males should comply with male activities and vice versa is a belief factor that will negatively or positively impact their learning of mathematics.

The summary of results reported in Table 3, indicated some activities are well-orientated or domain-disobedient (or domain fair). In other words, there was no significant difference between the mean scores of the male and female students in the well-orientated (WO) activities, $F(1,20)=$ 0.24 . This implies that both males and females could be considered comparable in the degree of involvement of activities of these types in the community where they are living in.

Thus, this study provided compelling evidence that the genders of the type outperform the other in its domain of activity and perform equally well in those that are gender disobedient. If both male and female students are engaged in everyday activities of mathematical significance in the community equally well, it is possible to assure comparable achievements in mathematical performance and in translating local knowledge to its equivalent mathematical knowledge.

\section{LiMITATIONS}

This study was constrained by several limitations. One critical limitation is the small number of participants $(n=20)$ will not allow much to generalize the results of the statistical inference as the mean scores can be highly affected by outliers. Secondly, the population of participants did not involve all abilities so that the finding needs support from all members of the community of learners. Thirdly, this study involved only one ethnic group, where there are more than 80 ethnic groups with diverse languages and having their own cultural backgrounds in the country. This issue can be addressed by including a considerable number of ethnic diversities of varied cultural backgrounds. 
With these limitations, however, this work can be considered as a stepping-stone for larger scale research, and can be regarded as initial research that may provide information on new views and possibilities in mathematics as a cultural product. Further research, involving more participants and researchers, is believed to provide and consolidate results that will have fundamental benefits for the educational community at large.

\section{Conclusions}

This exploratory study assessed whether the patterns observed in the literature-that gender-role socialization and stereotype threat as contributors of gender difference in mathematics learning-holds true with the high-achieving students with regard to local geometry.

Indeed, gender-role socialization as a major contributor of gender difference in mathematics learning was evident in the analysis of participants' responses to interview questions requiring participants: to describe a complete procedure of constructing daily materials, aspects that will affect the quality of the daily materials, mathematical ideas embedded in the constructions, and degree of engagement in the production of such daily materials and activities. The analyses of the participants' responses to these questions warrant two fundamental conclusions - the activities of mathematical significance are either gender-orientated or gender-free. That means there is an intelligible way to categorize everyday situations as: male-orientated, femaleorientated, and well/equally orientated activities. As evidenced from the analysis of the interview and mathematical questions, males and females perform better for their gender-related activities. In particular, the analysis of the mathematical questions indicated that participants demonstrate better performance and mathematical interpretation of the local artifact into its equivalent global representation in their corresponding genderorientated activities.

Those categorized as male-orientated activities are completely dedicated as males' work and those female-orientated are solely dedicated to females. In this case, having involvement in an opposite domain is realized as a taboo by the community - males ought to comply for males' work and females for females' work. In the well-orientated activities, both genders are fortunate to involve equally well. For instance, walking along a straight road is economical as compared with walking along any other line connecting any two points: curved, zigzag, or else. This is 
equally applicable to both genders, and hence no restriction is applicable. Making/applying fair shares of certain material among friends could equally be applicable to both genders as well.

It is argued that when students commence their mathematics learning based on their cultural background, they evidence high motivation to learning mathematics with meaning and thereby demonstrate high achievement. It also opens the opportunity for students to make mathematical connections, improve their ability in mathematical reasoning, and help students become better problem solvers.

Open Access This article is distributed under the terms of the Creative Commons Attribution 4.0 International License (http://creativecommons.org/ licenses/by/4.0/), which permits unrestricted use, distribution, and reproduction in any medium, provided you give appropriate credit to the original author(s) and the source, provide a link to the Creative Commons license, and indicate if changes were made.

\section{REFERENCES}

Alro, H., Skovsmose, O. \& Valero, P. (2007). Landscapes of learning in multicultural mathematics classrooms. CERME, 5(2007), 1567-1576.

Armstrong, J. M. (1981). Achievement and participation of women in mathematics: Results from two national surveys. Journal for Research in Mathematics Education, 12, 356-372.

Benbow, C. P. \& Stanley, J. C. (1983). Sex differences in mathematical reasoning ability: More facts. Science, 222, 1029-1031.

Bishop, A. (1988). Mathematics education in its cultural context. Educational Studies in Mathematics, 19(2), 179-191.

Bishop, A. (1991). Mathematics education in its cultural context. In M. Harris (Ed.), Schools mathematics and work. New York: Academic.

Bishop, A. (1992). Cultural issues in the intended, implemented and attained curriculum. In G. Leder (Ed.), Assessment and learning of mathematics (pp. 169-189). ACER.

Bishop, A. (1993). Influences from society. In A, Bishop, K, Hart, S, Lerman, and T, Nunes, (Eds.). Significant Influence on Children Learning of Mathematics (pp. 3-26). Paris, France: UNESCO.

Boaler, J. (1993). Encouraging the School Mathemtics to the "Real World" Through the Interaction of Process and Context, Context and Culture. Educational Studies in Mathematics, 25, 341-373.

Bush, W.S. (2005, July11). Improving research on mathematics learning and teaching in rural contexts. Journal of Research in Rural Education, 20(8). Retrieved May 20, 2013 from http://jrre.psu.edu/articles/20-8.pdf.

Clements, D. H. \& Battista, M. T. (1992). Geometry and spatial reasoning. In D. A. Grouws (Ed.), Handbook for research in mathematics education (pp. 420-464). New York: Macmillan. 
Cobb, P. (1999). Where is the Mind? In P. Murphy (Ed.), Learners, Learning, and Assessment (pp. 135-150). London: Paul Chapman publishing in association with the open university.

D'Ambrosio, U. (1985). Ethnomathematics and its place in the history and pedagogy of mathematic. For the Learning of Mathematics, 5(1), 44-48.

D'Ambrosio, U. (1990). The history of mathematics and ethnomathematics: How a native culture intervenes in the process of learning science. Impact of Science on Society, 40(4), 369-378.

De Abreu, G. \& Gorgorio, N. (2007). Social representations and multicultural mathematics. CERME, 5(2007), 1559-1566.

Deaux, K. \& Major, B. (1987). Putting gender into context: An interactive model genderrelated behavior. Psychological Review, 94, 369-389.

Dolinko, L. (1997). Investigating flags: A multicultural approach. Teaching Children Mathematics, 3(4), 186-190.

Dossey, J. A. (1992). The nature of mathematics: Its role and its influence. In D. A. Grouws (Ed.), Handbook for research in mathematics education (pp. 39-48). New York: Macmillan.

Dunn, D. (1988). The beginning of social understanding. Oxford: Blackwell.

Eccles, J. S. (1987). Gender roles and women's achievement-related decisions. Psychology of Women Quarterly, 11, 135-172.

Ernest, P. (1996). Varieties of constructivism: A framework for comparison. In L.P. Steffe \& P. Nesher (Eds.), Theories of mathematical learning. Chapter 20 (pp. 335-350). Mahwah, New Jersey: Erlbaum.

Ethington, C. \& Wolfe, L. M. (1984). Sex differences in a causal model of mathematics achievement. Journal for Research in Mathematics Education, 15, 361-377.

Fennema, E. H. \& Sherman, J. A. (1987). Sex-related differences in mathematics achievement and related factors: A further study. Journal for Research in Mathematics Education, 9, 189-203.

Gay, G. (2002). Culturally responsive teaching in special education for ethnically diverse students: Setting the stage. Qualitative Studies in Education, 15(6), 613-629.

Gerdes, P. (1985). Conditions and strategies for emancipator mathematics education in underdeveloped countries. For the Learning of Mathematics, 5(1), 15-20.

Gerdes, P. (2001). "Exploring the game of Julirde". Teaching Children Mathematics, 2, 321-327.

Gold, B. (2011). How your philosophy impacts your teaching. The Mathematical Association of America, 42(3), 174-182.

Goldberg, E. P., Cuoco, A. A. \& Mark, J. (1997). A role of geometry in general education. Waltham, MA: Education Development Centre Inc.

Hyde, J. S., Fennema, E. \& Lamon, S. J. (1990). Gender differences in mathematics performance: A meta-analysis. Psychological Bulletin, 107, 139-155.

Izmirli, I. M. (2011). Pedagogy on the ethnomatematics-epistemology nexus: A manifesto. Journal of Humanistic Mathematics, 1(2), 27-50.

Joseph, G. G. (2000). The crest of the peacock: Non-European roots of mathematics (2nd ed.). London: Penguin.

Kuhs, T. M. (1994). Portfolio assessment: Making it work the first time. The Mathematics Teacher Educator, 87(5), 332-335.

Leder, G. (1992). Mathematics and gender: Changing perspectives. In D. A. Grouws (Ed.), Handbook for research in mathematics education (pp. 597-622). New York: Macmillan. 
Leder, G. (2008). "Equity: The case for and against gender." Paper presented at ICME-11, Monterrey, Mexico.

Levine, D. U. \& Orbsteub, A. C. (1983). Sex differences in ability and achievement. Journal of Research and Development in Education, 16, 62-72.

Mallory, C. E. (1997). Including African students in the mathematics community. In J. Trencosta \& M. J. Kenney (Eds.), Multicultural and gender equity in the mathematics classroom: The gift of diversity (pp. 23-33). Reston, VA: National Council of Teacher of Mathematics.

Matang, R. (2002). The role of ethnomathematics in mathematics education in Papua New Guinea: Implications for mathematics curriculum. Journal of Educational Studies, 24(1), 27-37.

Moreira, D. (2007). Filling the gap between global and local mathematics. CERME, 5(2007), 1587-1596.

Moses, R. \& Cobb, C. (2001). Radical equations: Civil rights from Mississippi to the algebra project. Boston, MA: Beacon.

Nichol, R. \& Robinson, J. (2000). Pedagogical challenges in making mathematics relevant for indigenous Australians. International Journal for Mathematics Education, Science, and Technology, 31(4), 495-504.

Nieminen, P., Savinainen, A. \& Viiri, J. (2013). Gender differences in learning of the concept of force, representational consistency, and scientific reasoning. International Journal of Science and Mathematics Education, 11, 1137-1156.

Piaget, J. (1980). Adaptation and intelligence: Organic selection and phenocopy. Chicago: Chicago University Press.

Pinxten, R. (1994). Ethnomathematics and its practice. For the Learning of Mathematics, 14(2), 23-25.

Pollard, A. (2002). Reflective teaching: Effective and evidence-informed professional practice. London: Continuum.

Powell, A. B. \& Frankenstein, M. (Eds.). (1997). Ethnomathematics: Challenging Eurocentrism in mathematics education. Albany: State University of New York.

Presmeg, N. C. (1998). Ethnomathematics in teacher education. Journal of Mathematics Teacher Education, 1, 317-339.

Rogoff, B. (1999). Cognitive development through social interaction: Vygotsky and Piaget. In P. Murphy (Ed.), Learners, learning, and assessment (pp. 69-82). London: Paul Chapman Publishing in association with The Open University.

Rosa, M. \& Orey, D. C. (2010). Culturally relevant pedagogy: An ethnomathematical approach. Horizontes, 28(1), 19-31.

Spencer, S. J., Steele, C. M. \& Quinn, D. M. (1999). Stereotype threat and women's math performance. Journal of Experimental Social Psychology, 35, 4-28.

Stredder, K. (1999). Cultural bridging and children's learning. In P. Murphy (Ed.), Learners, learning and assessment (pp. 290-304). London: Paul Chapman Publishing in Association with The Open University.

Vithal, R. \& Skovsmose, O. (1997). The end of innocence: A critique of ethnomathematics. Educational Studies in Mathematics, 34, 131-157.

Von Glasersfeld, E. (1996). Aspects of radical constructivism and its educational recommendations. In L.P. Steffe \& P. Nesher. (Eds.), Theories of mathematics learning. Chapter 18 (pp. 307-314). Mahwah, New Jersey: Erlbaum.

Vygotsky, L. S. (1978). Mind and society: The development of higher psychological processes. Cambridge, MA: Harvard University Press. 
Zaslavsky, G. (1993). Multicultural mathematics: One road to the goal of mathematics for all. In G. J. Cuevas \& M. J. Driscoll (Eds.), Reaching all students with mathematics (pp. 45-55). Reston, VA: The National Council of Teachers of Mathematics, Inc.

Zaslavsky, C. (1994). "Africa counts" and ethnomathematics. For the Learning of Mathematics, 14(2), 3-8.

Zaslavsky, C. (1998). The multicultural mathematics classroom: Bringing in the world. Portsmouth, NH: Heinemann.

Mekelle Institute of Technology

Mekelle University

PO Box 1632, Mekelle, Ethiopia

E-mail: hwhnweld@gmail.com 